\title{
Produção fora de época da videira 'BRS Clara' sob cultivo protegido
}

\author{
Out of season production of 'BRS Clara' seedless grape under protected cultivation
}

\author{
Larissa Abgariani Colombo ${ }^{\mathrm{I}}$ Adriane Marinho de Assis"II Alessandro Jefferson Sato \\ Dauri José Tessmann ${ }^{\mathrm{III}}$ Werner Genta ${ }^{\mathrm{IV}}$ Sérgio Ruffo Roberto ${ }^{\mathrm{V}, 1}$
}

\section{RESUMO}

No norte do Paraná, a viticultura diferencia-se de outras regiões produtoras, pois são obtidas, nessa região, duas safras em um ano, uma regular e outra fora de época. Entretanto, o clima quente e úmido da região favorece a ocorrência do míldio (Plasmopara viticola) e uma alternativa para minimizar esse problema é o emprego do sistema de produção de uvas sob cultivo protegido. $O$ trabalho teve como objetivo avaliar a produção fora de época da videira 'BRS Clara' sobre os porta-enxertos 'IAC 572 Jales' $e$ 'IAC 766 Campinas', submetida à diferentes tipos de cultivo protegido. $O$ delineamento experimental empregado foi o de blocos ao acaso com quatro repetições, em arranjo fatorial $7 \times 2$ (sete tipos de cultivo protegido e dois porta-enxertos). Os tratamentos foram: a. sombrite sem fungicidas para míldio; $b$. sombrite com fungicidas para míldio (padrão de controle da região); $c$. cobertura plástica sem fungicidas para míldio; $d$. cobertura plástica e $50 \%$ de redução do padrão de fungicidas para míldio; e. cobertura plástica e $75 \%$ de redução do padrão de fungicidas para míldio; $f$. cobertura plástica com fosfito $e$ cobre; e g. cobertura plástica sem fungicidas. Os porta-enxertos 'IAC 766' e 'IAC 572' são indicados para a produção da uva sem semente 'BRS Clara' na região norte do Paraná; o emprego da cobertura plástica permite a redução de até $75 \%$ do número de aplicações de fungicidas no cultivo da uva 'BRS Clara', mas essa cobertura, por si só, não é suficiente para prevenir a ocorrência de míldio nos cachos, em condições de umidade elevada.

Palavras-chave: viticultura, cobertura plástica, uva apirena, produtividade.

\begin{abstract}
The viticulture of the north of Parana state differs from other regions, because in this area two crops are obtained a year, a regular and an out of season ones. However, the hot and humid climate of the region favors the occurrence of downy mildew (Plasmopara viticola), an alternative to minimize this problem is the use of grape production under protected cultivation. The study aimed to evaluate the out of season production of grapevine 'BRS Clara' on 'IAC 572 Jales' and 'IAC 766 Campinas' rootstocks, submitted to different types of protected cultivation. The randomized block design was used as a statistical model with four replications arranged in a factorial $7 \times 2$ (seven kinds of protected cultivation and two rootstocks). The treatments were: a. plastic screen without fungicides for downy mildew; $b$. plastic screen with fungicides for downy mildew (standard control of the region); c. plastic cover without fungicides for downy mildew; d. plastic cover and $50 \%$ of reduction of the standard fungicides for downy mildew; e. plastic cover and $75 \%$ of reduction for the standard fungicide mildew; $f$. plastic cover with phosphite and copper and; $g$. plastic cover without fungicides. The rootstocks 'IAC 766' and 'IAC 572' are suitable for the production of 'BRS Clara' in north of Parana state; the use of plastic cover allows a reduction up to $75 \%$ of the number of applications of fungicides in 'BRS Clara'; the plastic cover itself is not sufficient to prevent the occurrence of downy mildew in bunches under conditions of high humidity.
\end{abstract}

Key words: viticulture, plastic sheeting, seedless grape, productivity.

'Programa de Pós-graduação em Agronomia, Universidade Estadual de Londrina (UEL), Londrina, PR, Brasil.

IIPrograma Nacional de Pós-doutorado, Centro de Ciências Agrárias (CCA), UEL, Londrina, PR, Brasil.

II'Departamento de Agronomia, Universidade Estadual de Maringá (UEM), Maringá, PR, Brasil.

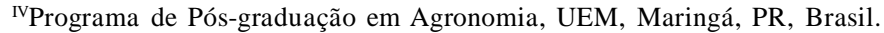

vDepartamento de Agronomia, UEL, CP 6001, 86051-990, Londrina, PR, Brasil. E-mail: sroberto@uel.br. Autor para correspondência. 


\section{INTRODUÇÃO}

No norte do Paraná, a viticultura diferenciase das demais regiões produtoras do país, devido às tecnologias de cultivo desenvolvidas e à dupla poda anual, obtendo-se duas safras em um ano (KISHINO et al., 2007). A primeira poda ou poda de inverno é realizada no fim do repouso hibernal, nos meses de julho e início de agosto, obtendo-se a colheita de dezembro a janeiro. A segunda poda ou poda de verão é realizada após a colheita proveniente da poda de inverno, obtendo-se uma produção fora de época entre maio e junho, período este em que a oferta de uvas de mesa no Brasil por outras regiões é baixa ou inexistente (ANZANELLO et al., 2010).

Entretanto, o clima quente e úmido durante o ciclo de produção da videira no norte do Paraná favorece a ocorrência de doenças fúngicas, como o míldio (Plasmopara viticola). Isso tem afetado a longevidade, a produtividade e a qualidade dos frutos, além de aumentar os custos, devido à intensa necessidade de controle dessa doença, que pode acarretar perdas de até $100 \%$ na produção (TESSMANN et al., 2007).

Uma alternativa para minimizar esses problemas é o emprego do sistema de produção de uvas sob cultivo protegido. A cobertura plástica tem sido empregada para minimizar os efeitos do clima durante as safras (MOTA et al., 2008), sobretudo pela redução da água livre sobre folhas e cachos, o que diminui a incidência de doenças fúngicas e a necessidade de pulverizações com defensivos químicos (CHAVARRIA et al., 2007), além de possibilitar modificações nas variáveis do microclima, como temperatura, radiação e vento (CARDOSO et al., 2008).

Outro fator importante quanto à produção da uva de mesa é a tendência da crescente demanda por uvas sem sementes, que vêm conquistando consumidores europeus, porém, no Brasil, a produção ainda é pequena (ARAÚJO, 2004). A uva sem semente, 'BRS Clara', tornou-se recentemente uma boa opção no norte do Paraná, pois, além de vigorosa e fértil, possui produtividade elevada (30t ha ${ }^{-1}$ ano $\left.^{-1}\right)($ CAMARGO et al., 2003).

Tendo em vista esses aspectos, o trabalho teve como objetivo avaliar a produção fora de época da videira 'BRS Clara' sobre os porta-enxertos 'IAC 572 Jales' e 'IAC 766 Campinas', submetida à diferentes tipos de cultivo protegido.

\section{MATERIAL E MÉTODOS}

O trabalho foi conduzido no município de Marialva (latitude $23^{\circ} 27^{\prime} 49,86^{\prime \prime}$ sul, longitude $51^{\circ} 47^{\prime} 18,74$ " oeste e altitude $614 \mathrm{~m}$ ), no norte do Estado do Paraná, durante as safras fora de época de 2008 e 2009. Foram utilizados dois porta-enxertos ('IAC 766 Campinas' e 'IAC 572 Jales') sob a cultivar copa de uva sem semente 'BRS Clara'. O plantio dos portaenxertos e a enxertia da variedade copa foram realizadas em julho de 2004 e julho de 2005, respectivamente, utilizando-se material propagativo livre de vírus, obtidos na Embrapa Uva e Vinho, Bento Gonçalves, RS.

As videiras foram conduzidas no sistema latada no espaçamento de 3,0m entre linhas e 4,0m entre plantas. As podas foram realizadas nas varas formadas na safra anterior, deixando-se 12 a 14 gemas vara $^{-1}$, sendo que apenas duas ou três gemas da ponta dessas varas foram estimuladas a brotar, aplicando-se cianamida hidrogenada a 2,0\%. As datas de poda e colheita de cada safra fora de época avaliada foram: safra 2008 - poda em 28/01/2008 e colheita em 23/05/ 2008; e safra 2009 - poda em 16/01/2009 e colheita em 07/05/2009.

O delineamento experimental foi em blocos ao acaso com quatro repetições, em arranjo fatorial 7x2 (sete tipos de cultivo protegido e dois porta-enxertos), sendo cada parcela composta por uma planta útil. Os tratamentos foram os seguintes tipos de cultivo protegido: $a$. sombrite sem fungicidas para míldio; $b$. sombrite com fungicidas para míldio (padrão de controle da região); $c$. cobertura plástica sem fungicidas para míldio; $d$. cobertura plástica e $50 \%$ de redução do padrão de fungicidas para míldio; $e$. cobertura plástica e 75\% de redução do padrão de fungicidas para míldio; $f$. cobertura plástica com fosfito e cobre; e $g$. cobertura plástica sem fungicidas.

Nos tratamentos $a$ e $b$, foi empregado sombrite no sistema de capela, na coloração preta com $18 \%$ de sombreamento e, nos tratamentos $c, d, e, f$, e $g$, foram utilizadas lonas plásticas trançadas de polipropileno, impermeabilizada com polietileno de baixa densidade (15 a 20\% de sombreamento), com 2,70m de largura e $150 \mu$ de espessura, aditivadas contra raios ultravioleta, posicionadas ao longo da linha de plantio, totalizando 10 fileiras. A cobertura plástica foi instalada sobre fios metálicos e arcos de ferro galvanizado de $3,0 \mathrm{~m}$, dispostos no parreiral a cada $2,0 \mathrm{~m}$, que, por sua vez, foram fixados sobre a estrutura de postes de eucalipto, que dá sustentação e forma ao sistema de condução. No espaço entre as linhas de plantio, permaneceram aberturas de aproximadamente $0,30 \mathrm{~m}$ (Figura 1).

O sistema de controle padrão da região (tratamento $b$ ) foi aplicado utilizando-se os seguintes defensivos de forma intercalar (nome do ingrediente ativo 

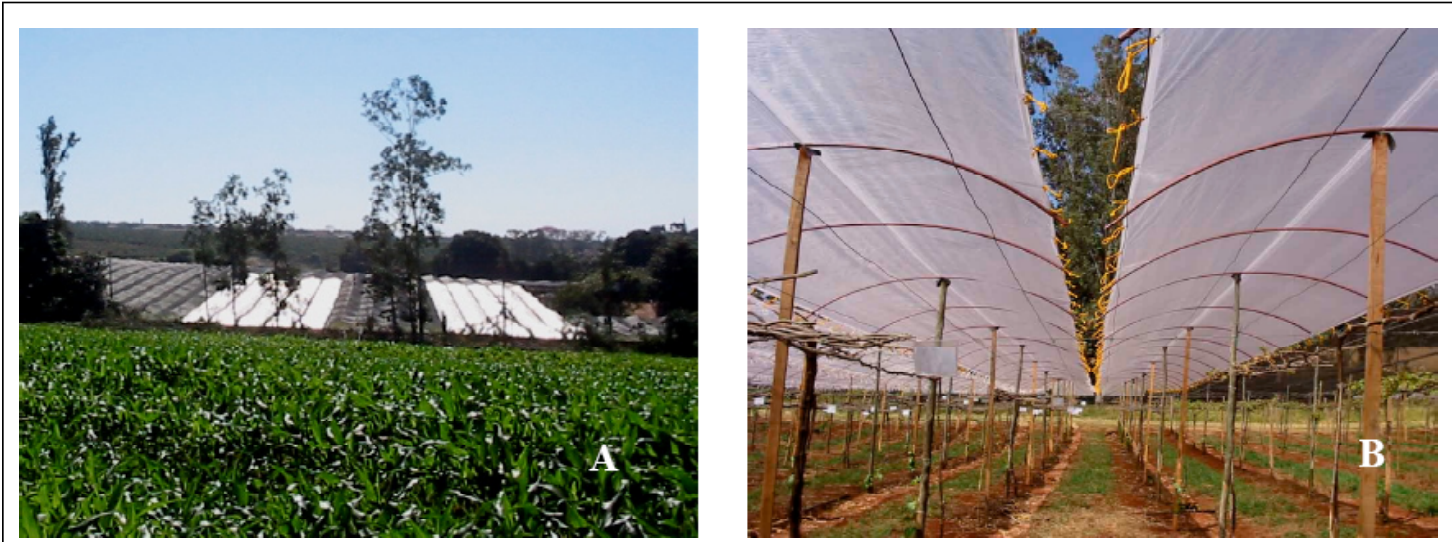

Figura 1 - A: Vista do experimento sob sombrite e cobertura plástica; B: Cobertura plástica recém-instalada.

e dosagem para 100L de água), num total de três a quatro aplicações a cada sete dias, tendo como alvo o míldio, a antracnose e o oídio: Metiram+Piraclostrobina $(0,20 \mathrm{~kg})$; Cymoxanil+Mancozeb (0,25kg); Cymoxanil+Mancozeb $(0,06 \mathrm{~kg})$; Metalaxil+Mancozeb $(0,25 \mathrm{~kg})$; Fenamidone $(0,03 \mathrm{~L})$; Iprovalicarbe+Propinebe $(0,25 \mathrm{~kg})$; Famoxadona+Mancozeb (0,12kg); Mancozeb $(0,3 \mathrm{~kg})$; Hidróxido de Cobre $(0,18 \mathrm{~kg})$; Difenoconazole $(0,012 \mathrm{~L})$; Tiofanato Metílico ( $0,07 \mathrm{~kg})$; Fenarimol (0,02L) e Captan $(0,24 \mathrm{~kg})$. Para o tratamento $f$, utilizaram-se duas a três aplicações dos produtos: Fosfito de Potássio (0,3L) e Hidróxido de Cobre $(0,18 \mathrm{~kg})$, a cada sete dias.

Nos tratamentos $a, b, c, d, e$ e $f$, foram aplicados fungicidas para o controle de oídio e, nos tratamentos $d \mathrm{e} e$, o número de aplicações de fungicidas para controle do míldio foi reduzido em 50 e $75 \%$, respectivamente, em relação ao número de aplicações empregado no tratamento fitossanitário padrão da região (tratamento $b$ ). Tendo em vista que as condições favoráveis para o surgimento das doenças fúngicas variou em função das condições climáticas, foram realizadas para os tratamentos $a, b, c, d, e, f$ e $g$ os seguintes números de aplicações de fungicidas, respectivamente: $0 ; 38 ; 0 ; 20 ; 12 ; 28$ e 0 , na safra de 2008 , e $0 ; 71 ; 13 ; 46 ; 33 ; 32$ e 0 , na safra de 2009 . As aplicações foram realizadas no início da brotação e se estenderam até 15 dias antes da colheita, sendo feitas através de pulverizador costal equipado com motor elétrico e válvula de pressão constante.

As variáveis climáticas como precipitação $(\mathrm{mm})$ e molhamento foliar no escuro (h) foram obtidas nos ambientes abaixo do sombrite e da cobertura plástica e fora do parreiral, a partir de três estações micrometeorológicas Metos (Pessl Instruments, Áustria), programadas para coletar os dados das variáveis climáticas a cada 12 minutos, com o objetivo de verificar a sua influência sobre o desenvolvimento das plantas e a intensidade das doenças (CARDOSO et al., 2008).

Foram avaliadas as seguintes variáveis: gemas brotadas por planta (\%), número de cachos por planta, massa dos cachos $(\mathrm{kg})$, produção por planta $\left(\mathrm{kg}\right.$ planta $\left.^{-1}\right)$ e produtividade $\left(\mathrm{t} \mathrm{ha}{ }^{-1}\right)$. A massa dos cachos foi quantificada em balança analítica. Os cachos foram colhidos manualmente, quando apresentaram 18 a $19^{\circ}$ Brix, com auxílio de tesoura de poda, sendo posteriormente submetidos à limpeza, retirando-se folhas ou ramos contidos entre as bagas, bagas danificadas, podres ou picadas por insetos. As características físicas e produtivas de cada safra foram analisadas por meio da análise de variância e a separação das médias foi realizada pelo teste de Tukey a $5 \%$ de probabilidade no aplicativo SISVAR, versão 4.3.

A porcentagem de ocorrência de míldio nos cachos foi avaliada a partir do início do enchimento das bagas, sendo a última avaliação realizada uma semana antes da colheita, através de amostragem em quatro ramos por parcela, dois de cada lado da planta, com um cacho por ramo, perfazendo quatro cachos (MADDEN et al., 2000). Os dados foram submetidos à análise de variância e a separação das médias foi realizada pelo teste Scott-Knott a 1\% de probabilidade, utilizando o aplicativo SISVAR, versão 4.3.

\section{RESULTADOS E DISCUSSÃO}

Não houve interação significativa entre os tipos de cultivo protegido para a variável porcentagem de gemas brotadas por planta na safra de 2008 (Tabela 1), entretanto, em relação aos porta-enxertos, o 'IAC 766' apresentou, para essa variável, média superior $(88,1 \%)$ em relação ao' IAC 572' $(77,9 \%)$. Durante a 
Tabela 1 - Características físicas e produtivas da videira 'BRS Clara' sobre os porta-enxertos 'IAC 572 Jales' e 'IAC 766 Campinas', submetida a diferentes tipos de cultivo protegido durante as safras fora de época de 2008 e 2009.

\begin{tabular}{|c|c|c|c|c|c|}
\hline & & & Safra 2008 & & \\
\hline Porta-enxertos (PE) & $\begin{array}{c}\% \text { de gemas } \\
\text { brotadas planta }^{-1}\end{array}$ & $\begin{array}{l}\mathrm{n}^{-} \text {de cachos } \\
\text { planta }^{-1}\end{array}$ & $\begin{array}{l}\text { massa dos } \\
\text { cachos (kg) }\end{array}$ & $\begin{array}{c}\text { produção } \\
\text { planta }^{-1 \text { b }}(\mathrm{kg})\end{array}$ & $\begin{array}{l}\text { produtividade }{ }^{\mathrm{d}} \\
\left(\mathrm{t} \mathrm{ha}^{-1}\right)\end{array}$ \\
\hline 'IAC 572 Jales' & $77,9 \mathrm{~b}$ & $35,6 \mathrm{~b}$ & $0,2 \mathrm{~b}$ & $12,6 \mathrm{~b}$ & $10,5 \mathrm{~b}$ \\
\hline 'IAC 766 Campinas' & 88,1 a & 43,9 a & 0,3 a & 17,3 a & $14,4 \mathrm{a}$ \\
\hline $\mathrm{F}$ & $25,59 *$ & $7,01 *$ & $13,19 *$ & $17,85^{*}$ & $17,85^{*}$ \\
\hline \multicolumn{6}{|l|}{ Tipos de Cultivo Protegido (TC) } \\
\hline Sombrite sem fungicidas para míldio al & $80,1 \mathrm{a}$ & - & - & - & - \\
\hline Sombrite com fungicidas (padrão) ${ }^{a /}$ & 84,8 a & 58,6 a & $0,4 \mathrm{a}$ & 26,2 a & 21,8 a \\
\hline Plástico sem fungicidas para míldio ${ }^{a /}$ & $83,3 \mathrm{a}$ & $16,8 \mathrm{~b}$ & $0,1 \mathrm{c}$ & $2,2 \mathrm{c}$ & $1,8 \mathrm{c}$ \\
\hline Plástico com 50\% redução do padrão ${ }^{a /}$ & 85,4 a & $51,0 \mathrm{a}$ & $0,4 \mathrm{a}$ & 22,8 a & 18,9 a \\
\hline Plástico com $75 \%$ redução do padrão ${ }^{a /}$ & $81,7 \mathrm{a}$ & 58,1 a & $0,4 \mathrm{a}$ & 24,1 a & 20,1 a \\
\hline Plástico com fosfito e cobre ${ }^{a /}$ & $85,2 \mathrm{a}$ & 42,3 a & $0,3 \mathrm{~b}$ & $12,8 \mathrm{~b}$ & $10,6 \mathrm{~b}$ \\
\hline Plástico sem fungicidas & 80,4 a & $11,5 \mathrm{~b}$ & $0,1 \mathrm{c}$ & $1,8 \mathrm{c}$ & $1,5 \mathrm{c}$ \\
\hline $\mathrm{F}$ & $0,71 \mathrm{~ns}$ & $28,95^{*}$ & $36,95^{*}$ & $66,12^{*}$ & $66,13 *$ \\
\hline F (interação PE x TC) & $1,07 \mathrm{~ns}$ & $1,30 \mathrm{~ns}$ & $0,49 \mathrm{~ns}$ & $2,30 \mathrm{~ns}$ & $2,30 \mathrm{~ns}$ \\
\hline $\mathrm{CV} \%$ & 9,09 & 27,41 & 22,38 & 25,60 & 25,61 \\
\hline Porta-enxertos (PE) & $\begin{array}{c}\% \text { de gemas } \\
\text { brotadas/ planta }\end{array}$ & $\begin{array}{l}\mathrm{n}^{\mathrm{o}} \text { de cachos } \\
\text { planta }^{-1}\end{array}$ & $\begin{array}{c}\text { Safra } 2009 \\
\text { massa dos } \\
\text { cachos (kg) }\end{array}$ & $\begin{array}{c}\text { produção } \\
\text { planta }^{\mathrm{b} /}(\mathrm{kg})\end{array}$ & $\begin{array}{l}\text { produtividade }{ }^{\mathrm{d}} \\
\qquad\left(\mathrm{t} \mathrm{ha}^{-1}\right)\end{array}$ \\
\hline 'IAC 572 Jales’ & $89,7 \mathrm{a}$ & $77,1 \mathrm{a}$ & $0,3 \mathrm{a}$ & $26,4 \mathrm{a}$ & $22,0 \mathrm{a}$ \\
\hline 'IAC 766 Campinas' & $90,5 \mathrm{a}$ & $69,7 \mathrm{a}$ & $0,3 \mathrm{a}$ & $21,4 \mathrm{~b}$ & $17,9 \mathrm{~b}$ \\
\hline $\mathrm{F}$ & $0,61 \mathrm{~ns}$ & $0,11 \mathrm{~ns}$ & $0,80 \mathrm{~ns}$ & $0,04^{*}$ & $0,04 *$ \\
\hline \multicolumn{6}{|l|}{ Tipos de Cultivo Protegido (TC) } \\
\hline Sombrite sem fungicidas para míldio a & $88,5 \mathrm{a}$ & - & - & - & - \\
\hline Sombrite com fungicidas (padrão) ${ }^{a /}$ & $90,3 \mathrm{a}$ & $129,5 \mathrm{a}$ & $0,4 \mathrm{a}$ & $47,8 \mathrm{a}$ & $39,9 \mathrm{a}$ \\
\hline Plástico sem fungicidas para míldio ${ }^{a /}$ & $89,7 \mathrm{a}$ & $14,9 \mathrm{c}$ & $0,2 \mathrm{ab}$ & $4,5 \mathrm{~b}$ & $3,7 \mathrm{~b}$ \\
\hline Plástico com $50 \%$ redução do padrão ${ }^{\text {a/ }}$ & $91,2 \mathrm{a}$ & $117,8 \mathrm{a}$ & $0,3 \mathrm{a}$ & 33,9 a & $32,4 \mathrm{a}$ \\
\hline Plástico com $75 \%$ redução do padrão ${ }^{a /}$ & 89,6 a & $108,3 \mathrm{a}$ & $0,4 \mathrm{a}$ & $38,1 \mathrm{a}$ & $31,7 \mathrm{a}$ \\
\hline Plástico com fosfito e cobre ${ }^{a /}$ & $91,7 \mathrm{a}$ & $57,8 \mathrm{~b}$ & $0,2 \mathrm{ab}$ & $12,9 \mathrm{~b}$ & $10,8 \mathrm{~b}$ \\
\hline Plástico sem fungicidas & 89,7 a & $12,1 \mathrm{c}$ & $0,1 \mathrm{~b}$ & $1,3 \mathrm{~b}$ & $1,10 \mathrm{~b}$ \\
\hline $\mathrm{F}$ & $0,55 \mathrm{~ns}$ & $0,00^{*}$ & $0,00^{*}$ & $0,00^{*}$ & $0,00^{*}$ \\
\hline F (interação PE x TC) & $0,71 \mathrm{~ns}$ & $0,74 \mathrm{~ns}$ & $0,33 \mathrm{~ns}$ & $0,20 \mathrm{~ns}$ & $0,20 \mathrm{~ns}$ \\
\hline $\mathrm{CV} \%$ & 14,22 & 21,40 & 55,12 & 33,81 & 33,81 \\
\hline
\end{tabular}

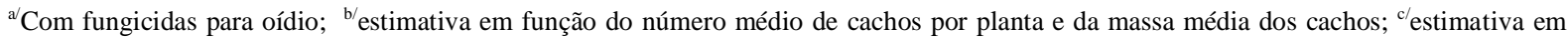
função da produção média por planta e do número de plantas por hectare; tratamento sem produção de cachos devido ao ataque de míldio. Médias seguidas da mesma letra nas colunas não diferem entre si pelo teste de Tukey $(\mathrm{P}<0,05)$. ${ }^{\text {ns }}$ não significativo, ${ }^{*}$ significativo $(\mathrm{P}<0,05)$.

safra de 2009 (Tabela 1), não foi observada interação entre os fatores porta-enxertos e tipos de cultivo protegido para a variável porcentagem de gemas brotadas, tampouco se observaram diferenças significativas dentro dos fatores. A porcentagem média de gemas brotadas por planta foi alta nessa safra (90\%), indicando que a cobertura plástica não afetou as características da brotação da videira 'BRS Clara'.

Na safra de 2008, foi observada interação entre os tipos de cultivo protegido e porta-enxertos para as variáveis número de cachos por planta e massa dos cachos (Tabela 1). Verificou-se que as médias do 'IAC 766' (43,9 cachos planta-1, cachos de $0,3 \mathrm{~kg}$ ) foram significativamente superiores às do 'IAC 572' (35,6 cachos planta-1, cachos de $0,2 \mathrm{~kg}$ ). FELDBERG et al. (2007), em Mocambinho-MG constataram que, na média das cinco safras avaliadas, o porta-enxerto '1103 Paulsen' induziu ao aumento de $50,6 \%$ no número de cachos, quando comparado ao 'IAC 572'. Em trabalho com o porta-enxerto 'IAC 766', no município de Sento Sé-BA, LEÃO (2002) obteve, com outras cultivares de uva sem semente, durante dois ciclos de produção, valores de 30,5 cachos planta ${ }^{-1}$ e cachos com $0,34 \mathrm{~kg}$.

Entre os tipos protegidos de cultivo, não se obtiveram cachos no tratamento sombrite sem fungicidas para míldio, o que indica que essa doença, 
quando não controlada nessas condições, resulta em total ausência de produção. Para as variáveis número de cachos por planta e massa dos cachos, apresentadas na tabela 1 , as menores médias foram observadas nos tratamentos com cobertura plástica sem fungicidas para míldio e sem fungicidas. Isso indica que, na safra fora de época, a presença do plástico por si só não previne a ocorrência do míldio nas videiras e, muito embora os tratamentos em que houve redução de 50 e $75 \%$ do número de aplicações tenham resultado em médias não significativamente distintas do tratamento sombrite com fungicidas padrão, é evidente que um número mínimo de aplicações de fungicidas em videiras cultivadas sob o plástico é necessário para o controle efetivo da doença.

Em relação ao número de cachos por planta e massa dos cachos durante a safra de 2009, não houve interação entre os fatores porta-enxertos e tipos de cultivo protegido (Tabela 1), também não foram observadas diferenças entre os porta-enxertos. Entretanto, para o fator tipos de cultivo protegido, verificou-se diferença entre os tratamentos. As maiores médias foram obtidas pelos tratamentos sombrite com fungicidas padrão e cobertura plástica com redução de 50 e $75 \%$ do número de aplicações de fungicidas. MOTA et al. (2008), trabalhando com a videira 'Cabernet Sauvignon' em Caxias do Sul, verificaram que o número de cachos por planta não foi influenciado pelos tratamentos com e sem cobertura e obtiveram em média 22,4 cachos planta ${ }^{-1}$. No presente trabalho, o número de cachos por planta foi influenciado pelos tipos de cultivo protegido, entretanto, a média de cachos por planta foi superior $(73,4)$ (Tabela 1$)$.

Durante as safras de 2008 e 2009, verificouse que, para as variáveis produção por planta e produtividade, não houve interação significativa entre os fatores (Tabela 1). Entretanto, na safra de 2008, as médias da 'BRS Clara', observadas sobre o 'IAC 766' $\left(17,3 \mathrm{~kg} \mathrm{planta}^{-1}\right.$ e $\left.14,4 \mathrm{t} \mathrm{ha}^{-1}\right)$ foram superiores às do 'IAC 572' (12,6kg planta ${ }^{-1}$ e 10,5 tha-1). Na safra de 2009, as médias da 'BRS Clara' sobre o 'IAC 572' (26,4kg planta $^{-1}$ e 22,0t ha ${ }^{-1}$ ) foram superiores às do 'IAC 766' $\left(21,4 \mathrm{~kg}\right.$ planta $^{-1}$ e 17,9t ha $\left.{ }^{-1}\right)$. Em comparação com a safra anterior, nota-se um acréscimo na produção e na produtividade entre os porta-enxertos em relação a essa safra, já que o 'IAC 572' acresceu em média 13,8kg planta $^{-1}$ e 11,5t ha ${ }^{-1}$ e o 'IAC 766' 4, $1 \mathrm{~kg}^{\text {p }}$ planta $^{-1}$ e 3,5t $\mathrm{ha}^{-1}$, comprovando-se o alto potencial produtivo da videira 'BRS Clara', conforme relatado por CAMARGO et al. (2003).

Nas safras de 2008 e 2009, em relação aos tipos de cultivo protegido (Tabela 1), as maiores médias foram obtidas nos tratamentos sombrite com fungicidas padrão, plástico com $50 \%$ de redução do padrão e plástico com $75 \%$ de redução do padrão, demonstrando que o uso da cobertura plástica, associada à redução do número de aplicações de fungicidas, resulta em alta eficiência do controle do míldio na videira 'BRS Clara'. Porém, o uso da cobertura plástica sem um número mínimo de aplicações de fungicidas resulta em produtividades inferiores, conforme observado na safra de 2008, nos tratamentos plástico sem fungicidas para míldio e plástico sem fungicidas. No tratamento sombrite sem fungicidas para míldio, nas safras de 2008 e 2009, a ausência de controle químico resultou na não obtenção de cachos, devido à severidade dessa doença sobre a uva 'BRS Clara' (Tabela 1).

Durante a safra de 2008, a influência dos porta-enxertos na ocorrência de míldio nos cachos não foi significativa (Tabela 2). Os tratamentos mais eficientes para o controle da doença foram plástico com $50 \%$ de redução do padrão e plástico com $75 \%$ de redução do padrão. O tratamento plástico sem fungicida para míldio não diferiu significativamente da testemunha sombrite sem fungicidas para míldio, com $100 \%$ dos cachos apresentando sintomas da doença. Nesse período, o clima foi altamente favorável ao progresso de míldio, devido ao elevado volume de precipitação pluviométrica e aos períodos prolongados de molhamento foliar no escuro, que foram, em média, 303,9mm e 462,6h, respectivamente, distribuídos com uniformidade na fase mais crítica para a ocorrência da doença, período este entre a segunda quinzena de fevereiro e a primeira quinzena de março de 2008.

Observou-se, na safra de 2008, que apenas a cobertura plástica não foi suficiente para prevenir a ocorrência de míldio nos cachos e que, sob condições de umidade elevada, ocorre o molhamento das folhas e cachos embaixo da cobertura plástica. Assim, estimase que a ausência de chuva embaixo da cobertura plástica reduziu a lavagem, degradação ou eliminação dos fungicidas depositados nas folhas e cachos, e isso contribuiu para a eficiência dos tratamentos, nos quais houve redução no número de aplicações de fungicidas.

Na safra de 2009, os porta-enxertos não exerceram influência na ocorrência de míldio nos cachos da videira 'BRS Clara'. Quanto ao tipo de cultivo protegido, apenas o tratamento sombrite sem fungicida diferiu significativamente dos demais, com a ocorrência de míldio em $84,1 \%$ dos cachos (Tabela 2). O clima foi bastante favorável ao progresso de míldio nessa safra, devido à elevada frequência e intensidade de precipitações pluviométricas e de períodos prolongados com molhamento foliar no escuro, que foram, em média, 390,6mm e 559,5h, respectivamente, sendo esses valores superiores aos obtidos na safra de 2008 . 
Tabela 2 - Ocorrência de míldio (Plasmopara viticola) nos cachos da videira 'BRS Clara' sobre os porta-enxertos 'IAC 572 Jales' e 'IAC 766 Campinas', submetida a diferentes tipos de cultivo protegido durante as safras fora de época de 2008 e 2009.

\begin{tabular}{|c|c|c|}
\hline & Safra 2008 & Safra 2009 \\
\hline Porta-enxertos (PE) & Ocorrência de míldio nos cachos (\%) & Ocorrência de míldio nos cachos (\%) \\
\hline 'IAC 572 Jales' & $60,7 \mathrm{a}$ & $13,4 \mathrm{a}$ \\
\hline 'IAC 766 Campinas' & 63,4 a & $15,2 \mathrm{a}$ \\
\hline $\mathrm{F}$ & $0,25 \mathrm{~ns}$ & $0,37 \mathrm{~ns}$ \\
\hline \multicolumn{3}{|l|}{ Tipos de Cultivo Protegido (TC) } \\
\hline Sombrite sem fungicidas para míldio ${ }^{a /}$ & $100,0 \mathrm{a}$ & $84,1 \mathrm{a}$ \\
\hline Sombrite com fungicidas (padrão) ${ }^{\mathrm{a} /}$ & $59,4 \mathrm{~b}$ & $0,0 \mathrm{c}$ \\
\hline Plástico sem fungicidas para míldio a/ & $100,0 \mathrm{a}$ & $0,0 \mathrm{c}$ \\
\hline Plástico com 50\% redução do padrão ${ }^{a /}$ & $0,0 \mathrm{c}$ & $0,0 \mathrm{c}$ \\
\hline Plástico com 75\% redução do padrão a/ & $6,3 \mathrm{c}$ & $3,1 \mathrm{c}$ \\
\hline Plástico com fosfito e cobre ${ }^{a /}$ & $68,8 \mathrm{~b}$ & $0,0 \mathrm{c}$ \\
\hline Plástico sem fungicidas & $100,0 \mathrm{a}$ & $12,5 \mathrm{c}$ \\
\hline $\mathrm{F}$ & $38,08 * *$ & $60,37 * *$ \\
\hline F (interação PE x TC) & $0,12 \mathrm{~ns}$ & $0,14 \mathrm{~ns}$ \\
\hline $\mathrm{CV} \%$ & 30,0 & 46,7 \\
\hline
\end{tabular}

${ }^{a}$ Com fungicidas para oídio.

Médias seguidas da mesma letra nas colunas não diferem entre si pelo teste de Scott-Knott $(\mathrm{P}<0,01)$. ${ }^{\text {ns }}$ não significativo, **significativo $(\mathrm{P}<0,01)$. As médias apresentadas não estão transformadas, no entanto, os agrupamentos dos tratamentos estimados pelo teste de média para a porcentagem de míldio nos cachos foram calculados com dados originais transformados para $\sqrt{\mathrm{x}+1}$.

O uso da cobertura plástica permitiu que a colheita se processasse em situações mais favoráveis durante as safras avaliadas, ou seja, os cachos sob a cobertura plástica foram colhidos secos, não havendo a necessidade de expô-los à ventilação durante o processo de pós-colheita.

Pelos resultados obtidos durante as safras de 2008 e 2009, o emprego de cobertura plástica permite reduzir em até $75 \%$ do número de aplicações de fungicidas, sem prejudicar as características físicas e produtivas da videira 'BRS Clara', demonstrando ser uma tecnologia promissora, que se tornou competitiva na produção de uvas sem sementes na região norte do Paraná.

\section{CONCLUSÃO}

Os porta-enxertos 'IAC 766' e 'IAC 572' são indicados para a produção de uva sem semente 'BRS Clara' na região norte do Paraná, durante as safras fora de época e o emprego da cobertura plástica permite a redução de até $75 \%$ do número de aplicações de fungicidas. Entretanto, a cobertura plástica por si só não é suficiente para prevenir a ocorrência de míldio nos cachos, em condições de umidade elevada.

\section{REFERÊNCIAS}

ANZANELLO, R. et al. Uso da poda seca e da poda verde para obtenção de duas safras por ciclo vegetativo em três cultivares de videira. Revista Brasileira de Fruticultura, Jaboticabal, v.32, n.1, p.196-203, 2010. Disponível em: <http:// www.scielo.br/scielo.php?script $=$ sci_arttext $\&$ pid $=S$ $010029452010000100022 \& \operatorname{lng}=\mathrm{pt} \& \mathrm{nrm}=\mathrm{iso}>$. Acesso em: 5 maio, 2010. doi: 10.1590/S0100-29452010005000027.

ARAÚJO, J.L.P. Cultivo da videira. Embrapa Semi-Árido, 2004. Acesso em: 18 maio, 2009. Online. Disponível em: <http://www.sistemasdeprodução.cnptia.embrapa.br/fonteshtml/ Uva/Cultivoda Videira/custos.htm>.

CAMARGO, U.A. et al. BRS Clara: nova cultivar de uva branca de mesa sem semente. Bento Gonçalves: Embrapa Uva e Vinho, 2003. 4p. (Comunicado Técnico, 46).

CARDOSO, L.S. et al. Alterações micrometeorológicas em vinhedos pelo uso de coberturas de plástico. Pesquisa Agropecuária Brasileira, Brasília, v.43, n.4, p.441-447, 2008.

CHAVARRIA, G. et al. Incidência de doenças e necessidade de controle em cultivo protegido de videira. Revista Brasileira de Fruticultura, Jaboticabal, v.29, n.3, p.477-482, 2007. Disponível em: <http:// www.scielo.br/scielo.php? script $=$ sci_arttext $\&$ pid $=$ S0 100 29452007000300014\&lng=pt\&nrm=iso>. Acesso em: 5 maio, 2010. doi: 10.1590/S0100-29452007000300014. 
FELDBERG, N.P. et al. Desempenho agronômico das videiras 'Crimson Seedless' e 'Superior Seedless' no Norte de Minas Gerais. Pesquisa Agropecuária Brasileira, Brasília, v.42, n.6, p.777-783, 2007.

KISHINO, A.Y. et al. Planejamento e administração: gerenciamento da produção. In: KISHINO, A.Y. et al. Viticultura tropical: o sistema de produção do Paraná. Londrina: Iapar, 2007. p.45-52.

LEÃO, P.C. da S. Comportamento das variedades de uva sem sementes Crimson Seedless e Fantasy Seedless no Submédio do Vale do São Francisco. Revista Científica Rural, Bagé, v.7, n.1, p.85-94, 2002.
MADDEN, L.V. et al. Evaluation of a disease warning system for downy mildew of grapes. Plant Disease, Saint Paul, v.84, p.549-554, 2000 .

MOTA, C.S. et al. Comportamento vegetativo e produtivo de videiras 'Cabernet Sauvignon' cultivadas sob cobertura plástica. Revista Brasileira de Fruticultura, Jaboticabal, v.30, n.1, p.148-153, 2008. Disponível em: <http://www.scielo.br/ s c i e lo.ph p s c ri p t $=$ s c i a r t ex t \& pi d $=$ S 01 $0029452008000100027 \& \operatorname{lng}=$ pt $\& \mathrm{nrm}=\mathrm{iso}>$. Acesso em: 5 maio, 2010. doi: 10.1590/S0100-29452008000100027.

TESSMANN, D.J. et al. Doenças e seu manejo: doenças fúngicas. In: KISHINO, A.Y. et al. Viticultura tropical: o sistema de produção do Paraná. Londrina: Iapar, 2007. p.255-287. 